\title{
Article
}

\section{Optically Switchable MeV Ion/Electron Accelerator}

\author{
Itamar Cohen 1,2,*, Yonatan Gershuni ${ }^{1,2}$, Michal Elkind ${ }^{1,2}$, Guy Azouz ${ }^{1,2}$, Assaf Levanon ${ }^{1,2}$ and \\ Ishay Pomerantz 1,2 (D) \\ 1 The School of Physics and Astronomy, Tel Aviv University, Tel-Aviv 69978, Israel; \\ gershuni@mail.tau.ac.il (Y.G.); michalelkind@mail.tau.ac.il (M.E.); guyazouz@mail.tau.ac.il (G.A.); \\ levanonster@gmail.com (A.L.); ipom@tauex.tau.ac.il (I.P.) \\ 2 Center for Light-Matter Interaction, Tel Aviv University, Tel-Aviv 69978, Israel \\ * Correspondence: Itamarcohen1@mail.tau.ac.il
}

Citation: Cohen, I.; Gershuni, Y.; Elkind, M.; Azouz, G.; Levanon, A.; Pomerantz, I. Optically Switchable $\mathrm{MeV}$ Ion/Electron Accelerator. Appl. Sci. 2021, 11, 5424. https://doi.org/ 10.3390/app11125424

Academic Editor: Daniele Margarone

Received: 2 May 2021

Accepted: 3 June 2021

Published: 10 June 2021

Publisher's Note: MDPI stays neutral with regard to jurisdictional claims in published maps and institutional affiliations.

Copyright: (c) 2021 by the authors. Licensee MDPI, Basel, Switzerland. This article is an open access article distributed under the terms and conditions of the Creative Commons Attribution (CC BY) license (https:/ / creativecommons.org/licenses/by/ $4.0 /)$.
Featured Application: We demonstrate in this letter a laser-based accelerator that switches between generating beams of either multi-MeV electrons or ions by a simple optical manipulation. We analyze its applicability in terms of energy, charge, divergence, and repeatability. The versatility of this accelerator may enable various applications in industry and research, which are presented in the paper.

Abstract: The versatility of laser accelerators in generating particle beams of various types is often promoted as a key applicative advantage. These multiple types of particles, however, are generated on vastly different irradiation setups, so that switching from one type to another involves substantial mechanical changes. In this letter, we report on a laser-based accelerator that generates beams of either multi-MeV electrons or ions from the same thin-foil irradiation setup. Switching from generation of ions to electrons is achieved by introducing an auxiliary laser pulse, which pre-explodes the foil tens of ns before irradiation by the main pulse. We present an experimental characterization of the emitted beams in terms of energy, charge, divergence, and repeatability, and conclude with several examples of prospective applications for industry and research.

Keywords: laser electron acceleration; laser proton acceleration; high-intensity lasers; non-destructive testing; elemental analysis

\section{Introduction}

The invention of chirped pulse amplification [1], for which the 2018 Nobel Prize in Physics was awarded, introduced the era of multi-petawatt lasers [2] and led to new regimes of light-matter interaction. The most striking feature of intense laser interaction with solid targets is the emission of a variety of intense radiation types [3], including electrons, ions, $x$-rays, and positrons. The relatively small scale of these lasers earned these machines the moniker "tabletop accelerators" and triggered research ranging from small portable machines [4] to large facilities [5] and accelerators at the energy frontier [6].

The relatively small size and cost of laser accelerators is often promoted as their main advantage [7]. Another appealing characteristic is their ability to transport the beam over optical mirrors for most of the way [8] and generate the particle beam close to the interaction point. Consequently, radiation shielding of laser accelerators is simpler than that of conventional accelerators with comparable energies [9].

The ultrashort nature of laser-accelerated particle bunches has also been deemed advantageous for applications [10] and research [11]. This capability is further reflected by the possibility of synchronizing the particle emission with another laser or particle pulse, with sub-ps temporal jitter [12,13].

The lion's share of laser-particle acceleration research focuses on acceleration of ions and electrons. One distinct experimental difference between these two types of research is 
that electron acceleration usually involves gaseous targets, whereas most ion acceleration experiments are conducted by irradiation of solids.

Laser acceleration of ions to $\mathrm{MeV}$ level energies was introduced more than 2 decades ago $[14,15]$ with the target-normal sheath acceleration (TNSA) [16] mechanism. Higher laser intensities and improved pulse contrast promoted more robust acceleration mechanisms, such as the breakout afterburner [17], which rely on opaque plasma becoming relativistically transparent, and radiation pressure acceleration [18] in which electrons are compressed to a highly dense layer that in turn accelerates ions.

In all these experiments, the highest energy ions are generated from sub- $\mu \mathrm{m}$-thick foil targets. Several methods for replenishing such targets at a high rate were devised in the form of, e.g., thin sheets of liquid ethylene glycol [19] or hydrogen, which solidify when injected into vacuum [20], or with automatically positioned [21] micro-machined foil targets [22].

Gas targets are naturally easier to refresh. High-energy ion beams resulting from collisionless shockwaves induced in nearly critical gas targets were demonstrated by either using long-wavelength laser pulses [23] or with very high-density gas [12,24-26]. Tailoring the plasma profile around a solid foil target to enhance the emission of TNSA ions was also recently investigated [27].

Gaseous targets are a common choice for laser generation of high-quality electron beams. For the past 2 decades, the laser wakefield community focused on optimizing the accelerated beam quality for higher particle energy [28], sharper energy spectrum [29], higher charge [30], and improved repeatability.

A few early works identified an electron acceleration technique from solid foil targets, referred to as "the exploding foil method (EXFM)" [31]. With EXFM, low-energy light preceding the main pulse turns the foil into an expanding plume of plasma. Owing to the expansion of the plasma, the electron density falls below the critical value and becomes transparent to the main pulse, which arrives tens of ns later. The main pulse forms selfguided laser wakefield structures [32], which generates ultra-collimated, multi-MeV beams of electrons [33].

Compared to modern wakefield electron acceleration schemes, EXFM seemed noncompetitive on maximum energy and a peaked spectrum. Nevertheless, the laser-toelectron energy conversion efficiency of this scheme is unprecedented, making it ideal for generating a large number of photo-nuclear reactions [11,33].

In previous studies, foil targets were exploded by pre-pulses native to the laser system, which could not be manipulated. Here we present a first experimental study in which electron beams are generated with EXFM in an engineered manner, i.e., with an auxiliary controlled pre-pulse. The study was enabled by the pristine intrinsic contrast of our laser system presented in Figure 1. In this letter, we show how by the mere introduction of this pre-pulse (illustrated in red in Figure 1), our setup switches from generation of TNSA ions to generating EXFM electrons.

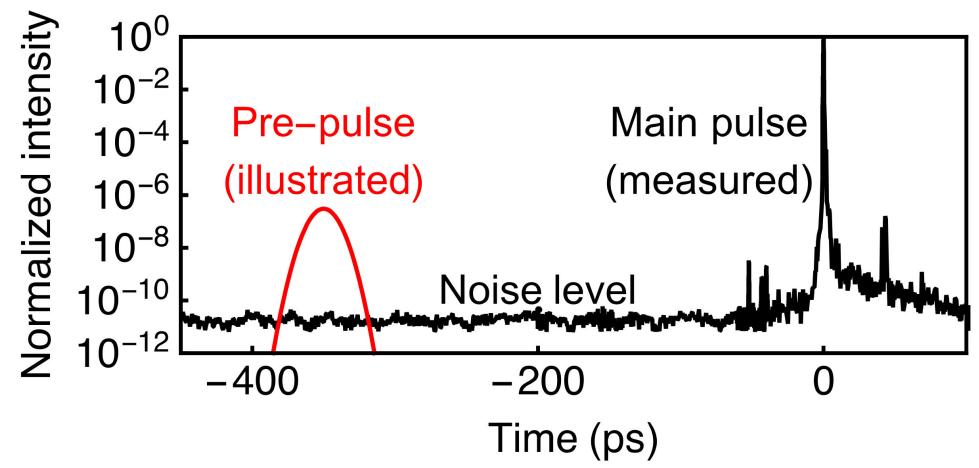

Figure 1. The temporal profile of the NePTUN laser system (black), measured with a Sequoia thirdorder auto-correlator [34]. The $10^{-10}$ background is the diagnostic noise level, forming a lower limit at $\mathrm{t}=-50 \mathrm{ps}$. The auxiliary pre-pulse is illustrated in red. 


\section{Experimental Setup}

We performed the experiments using the NePTUN 20 TW laser system [35] at Tel Aviv University. A schematic drawing of the setup is shown Figure 2. Laser pulses of $29 \mathrm{fs}$ at reduced energy of $140 \mathrm{~mJ}$ were focused using an $\mathrm{f} / 2.5$ off-axis parabolic mirror having an effective focal length of $12.7 \mathrm{~cm}$ unto $800 \mathrm{~nm}$-thick Au foil targets. A measurement showed $70 \%$ of the laser energy to be contained within a circle of $4.1-\mu \mathrm{m}$ diameter, which corresponds to an intensity of $1.2 \times 10^{19} \mathrm{~W} / \mathrm{cm}^{2}$. The energy stability of the laser was measured to be $1.3 \%$ (RMS). The study relied on our automatic target system [21], which delivered the targets to the laser focus at a rate of $0.2 \mathrm{~Hz}$.

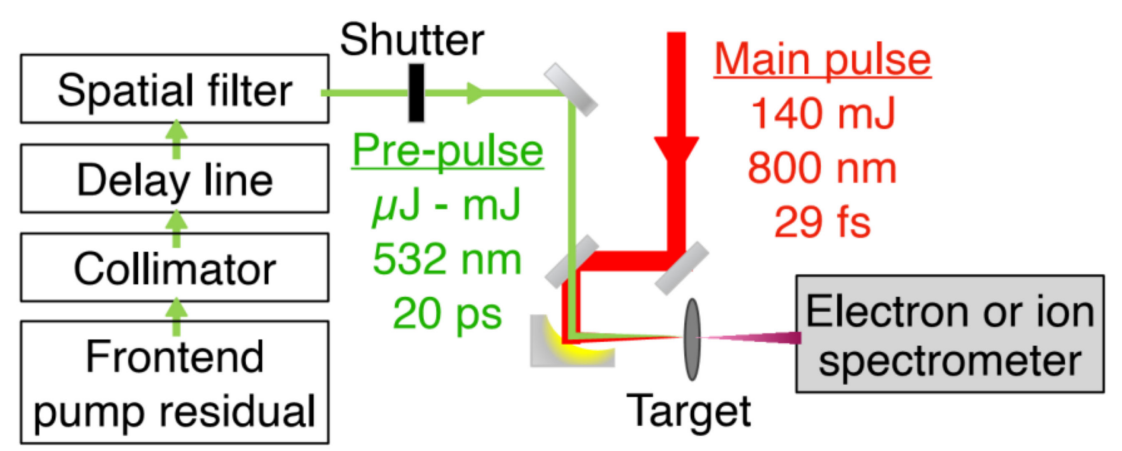

Figure 2. Schematic illustration of the irradiation setup. The main pulse (red) is focused using an off-axis parabolic mirror. The pre-pulse (green) is injected collinearly with the main pulse. Either a magnetic spectrometer or a Thomson parabola ion spectrometer is placed downstream to the generated beam.

We employ the residual energy from the frontend pump laser as the light source for the engineered pre-pulses. These $\lambda=532 \mathrm{~nm}, \mathrm{E}=30 \mu \mathrm{J}, \tau=20$ ps laser pulses are optically synchronized with the main pulse. The optical period and pulse duration of these pre-pulses are much shorter than the plasma expansion time, so their exact values should not affect the plasma heating in a significant manner. Our measurements found that 70 percent of the pre-pulse energy was contained within a circle of $8.1 \mu \mathrm{m}$ diameter, which corresponds to an intensity of $9.3 \times 10^{11} \mathrm{~W} / \mathrm{cm}^{2}$. The energy stability of the pre-pulse was measured to be $1.5 \%$ (RMS). The temporal jitter between the pre- and main-pulses was measured be shorter than $20 \mathrm{ps}$. These properties correspond to a contrast ratio of $8 \times 10^{-8}$ between the pre- and main-pulses. Before focusing, the pre-pulses are spatially filtered, collimated, and delayed in a variable delay line. A relative delay of 0-90 ns between the pre- and main pulses is achieved using our multi-plane "Cat's cradle" [36] delay line.

We measured the emitted electron and ion spectra for irradiation with or without auxiliary pre-pulses preceding the main pulse by $4 \mathrm{~ns}$ to $30 \mathrm{~ns}$. Electrons were measured using a magnetic spectrometer with a field strength of $0.15 \mathrm{~T}$ and an angular acceptance of $0.12 \mathrm{msr}$. Ions were measured with a Thomson parabola ion spectrometer (TPIS) with a similar design to that of Morrison et al. [37], operating with an electrode voltage difference of $1 \mathrm{kV}$ and having an angular acceptance of $0.10 \mathrm{msr}$. For both spectrometers, spectra were recorded by a charge-coupled device imaging a $\mathrm{CsI}(\mathrm{Tl})$ scintillator at the focal plane of the spectrometer. We obtained the absolute charge calibration of the electron spectrometer by acquiring the scintillation signal of a ${ }^{90} \mathrm{Sr}$ calibration beta emitter placed behind the scintillator, using the same imaging system.

\section{Results}

Recorded raw spectrograms are shown in Figure 3, for shots with and without a pre-pulse. The results feature two distinct modes of operation: for irradiation without a pre-pulse, the TPIS trace matches an ion beam with proton cut-off energy of more than $1 \mathrm{MeV}$, while a very low signal is recorded by the electron spectrometer. With pre-explosion 
at $\mathrm{t}=-22 \mathrm{~ns}$, a beam of electrons with energies exceeding $3 \mathrm{MeV}$ is recorded, and nearly no ions. The lack of TNSA ions indicates complete destruction of the target.

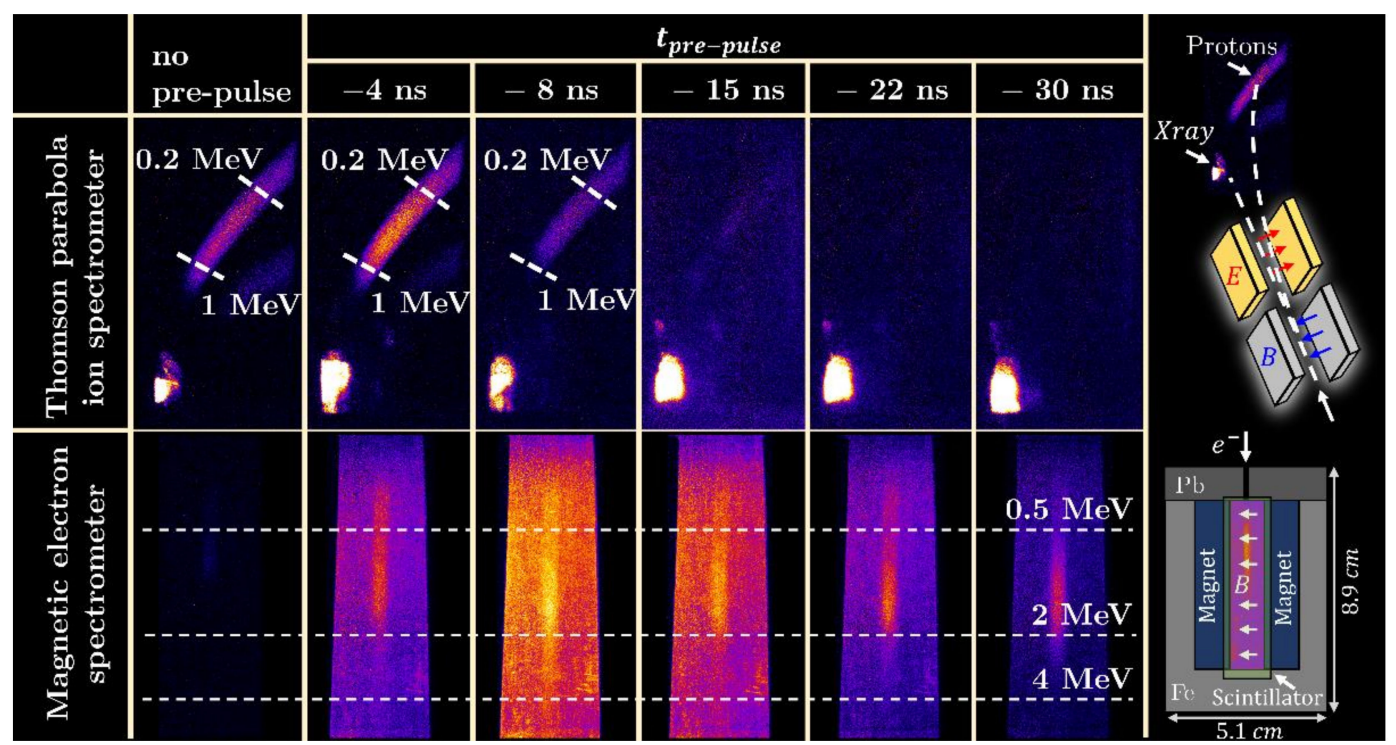

Figure 3. Raw ion (top row) and electron (bottom row) spectrograms obtained with different pre-pulse delays. The schematics of the two spectrometers are illustrated on the right.

The analyzed electron (blue) and proton (red) spectra are shown in Figure 4a. The electron spectra were recorded for shots with a relative delay of $t=-22 \mathrm{~ns}$. The shaded areas represent the standard deviation between 11 consecutive shots for the electrons and 14 consecutive shots for the protons. The electron spectrum recorded on a shot without a pre-pulse is shown in dashed blue. The total electron charge is more than an order of magnitude lower than the proton number and has a cutoff energy of about $1 \mathrm{MeV}$.

(a)

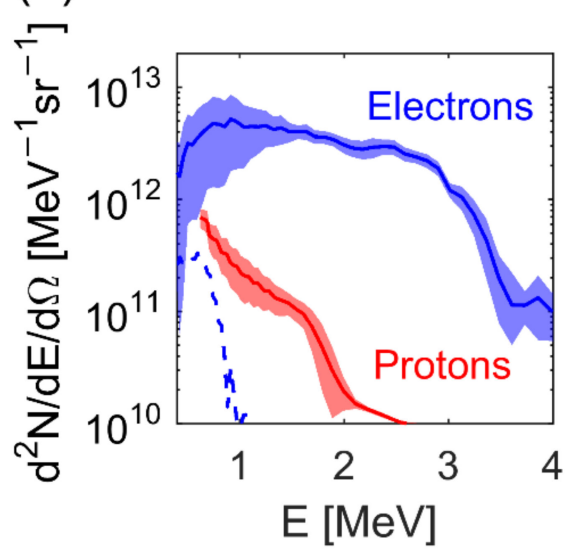

(b)

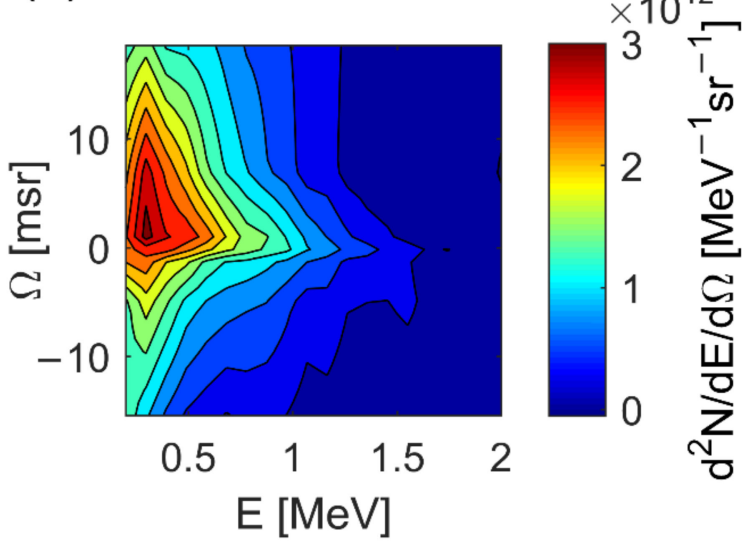

Figure 4. (a) Proton spectra from 14 consecutive shots without pre-pulse (red) and electron spectra from 11 consecutive shots with $t=-22$ ns pre-pulses (blue). The shaded area represents the standard deviation between shots. The recorded electron spectrum of a shot without a pre-pulse is shown in dashed blue. (b) Charge spatial-spectral distribution of the electron beam.

We measured the electron divergence by translating the electron spectrometer across the beam in 7 different positions. The result, presented in Figure $4 b$, features an average divergence of $10 \mathrm{msr}$. 


\section{Discussion}

Several potential applications may benefit from this irradiation scheme. Energydispersive x-ray (EDX) [38] spectroscopy and particle-induced x-ray emission (PIXE) [39] are two powerful techniques for material analysis. They are widely used in the semiconductor industry $[40,41]$ and in biomedical applications [42,43]. EDX reveals the elemental composition of solid samples, while PIXE resolves $\sim \mu \mathrm{m}$-deep stratigraphic structures. Both methods rely on measuring $x$-rays emitted from a sample, following its irradiation with particle beams in the keV-to-MeV energy range. Laser-driven EDX was recently demonstrated [44], using a mixed beam of laser-accelerated electrons and protons emitted from irradiated solid foils. Laser-driven PIXE was demonstrated on the same setup, by sweeping out the electrons with a magnetic field. Our acceleration scheme, which would amount to adding the controlled pre-pulse to this setup, can enable EDX with a 1000 times brighter beam of electrons in the $\mathrm{MeV}$ range (compare dashed to solid blue curves in Figure 4a). If necessary, removal of these excess electrons using magnetic deflection may be applied to this setup as well. Proton energies of over $3 \mathrm{MeV}$, which are the requirement for conducting PIXE, may be obtained using a 100 TW-class laser system.

Particle beams in the $\mathrm{MeV}$ energy range are also used for conducting non-destructive testing (NDT). Example applications include the investigation of trucks and cargo containers [45] for detecting the contraband of explosives [46], narcotics [47], and special nuclear materials [48]. The use of $\gamma$-rays has already reached commercial maturity [49], but the applicability of other beam types is limited by the titanic dimensions of conventional particle accelerators.

With shadowgraphy, the simplest form of NDT, information is revealed by the fraction of particles transmitted through the interrogated sample. Using multiple types of radiation may reveal details that are not obtained by each beam type by itself [50]. We illustrate this idea in Figure 5, which shows the simulated transmission of $10 \mathrm{MeV}$ protons (left) and electrons (right) through a sample of $600 \mu \mathrm{m}$ thick coaxial cylinders made of $\mathrm{Al}, \mathrm{W}$, and $\mathrm{Cu}$.

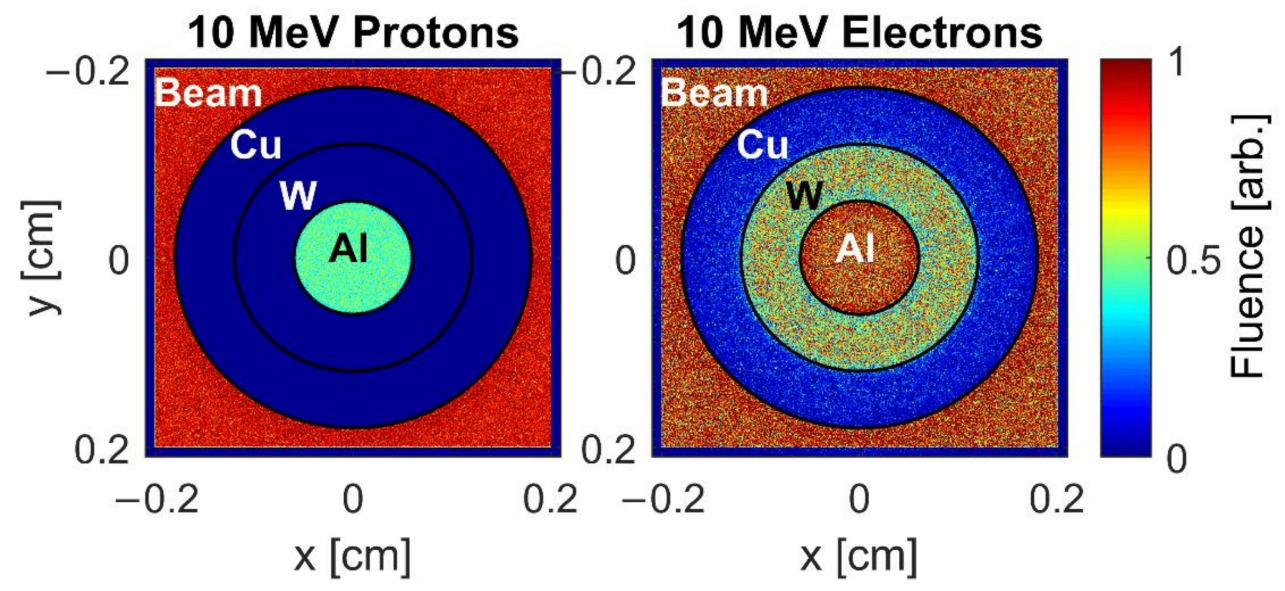

Figure 5. Particle transport simulation of the transmission of $10 \mathrm{MeV}$ proton (left) and electron (right) beams passing through a sample of $600 \mu \mathrm{m}$ thick $\mathrm{Al}, \mathrm{W}$, and $\mathrm{Cu}$. The color scale is normalized to the beam fluence.

The simulation was conducted with the FLUKA particle transport simulation code [51]. Figure 5 shows that the $\mathrm{Al}$ casts a $\sim 50 \%$ shadow on the proton beam, whereas the $\mathrm{W}$ and $\mathrm{Cu}$ shadows are absolute and indistinguishable. The electron beam, however, reveals a difference between the two heavier metals, but the $\mathrm{Al}$ is nearly $100 \%$ transparent.

For nuclear physics research, the ability to switch between beams of electrons and ions within $>1 \mathrm{~Hz}$ may be applied to study ${ }^{\mathrm{A}} Z(\mathrm{p}, \mathrm{x})$ reactions, on isotopes with $\mathrm{O}(1 \mathrm{~s})$ lifetimes. A sample of long-lived ${ }^{\mathrm{A}+1} \mathrm{Z}$ isotope, e.g., ${ }^{56} \mathrm{Ni}$, may be irradiated with $\mathrm{MeV}$ electrons to induce the ${ }^{56} \mathrm{Ni}(\gamma, \mathrm{n})^{55} \mathrm{Ni}$ reaction by bremsstrahlung. The resulting ${ }^{55} \mathrm{Ni}$ has a half-life of $\mathrm{T}_{1 / 2}=204 \mathrm{~ms}$ [52]. Measurements of the ${ }^{55} \mathrm{Ni}(\mathrm{p}, \gamma)$ reaction, which is important 
for determining whether the rp-process bypasses the ${ }^{56} \mathrm{Ni}$ waiting point [53], may then be made in situ.

\section{Conclusions}

In this letter, we reported on the applicable aspects of a laser particle acceleration scheme, in which beams of either $\mathrm{MeV}$ electrons or ions are chosen by opening or closing an optical shutter. The plasma dynamics governing EXFM has rich dependence on the pre-pulse energy and delay, and on the target material and thickness. One aspect which is important for applications, is the scaling of the electron energy with higher laser intensities and the required pre-pulse parameters. On a Petawatt laser, for example, we generated electron beams with a temperature of $10.5 \mathrm{MeV}$ by irradiating plastic target foils with laser energy of $E=90 \mathrm{~J}$, pulse duration of $150 \mathrm{fs}$ and an intrinsic pre-pulse energy of about $1 \mu \mathrm{J}$ preceding the main pulse by $60 \mathrm{~ns}$ [11]. An investigation of these aspects will be the subject of a future publication.

Author Contributions: Conceptualization, I.P.; methodology, I.C., Y.G. and M.E.; software, G.A.; validation, Y.G. and M.E.; formal analysis, I.C. and Y.G.; writing —original draft preparation, I.C.; writing - review and editing, I.P. and I.C.; supervision, I.P. and A.L.; project administration, A.L.; funding acquisition, I.P. All authors have read and agreed to the published version of the manuscript.

Funding: The study was supported by Israel Ministry of Energy grant no. 220-11-054 and by the Zuckerman STEM Leadership Program. I.C. acknowledges support by the Jabotinsky Fellowship of the Ministry of Science and Technology, Israel.

Data Availability Statement: The data that support the findings of this study are available from the corresponding author upon reasonable request.

Acknowledgments: We acknowledge aid in target fabrication from the Tel Aviv University Center for Nanoscience and Nanotechnology.

Conflicts of Interest: The authors declare no conflict of interest.

\section{References}

1. Strickland, D.; Mourou, G. Compression of amplified chirped optical pulses. Opt. Commun. 1985, 56, 219-221. [CrossRef]

2. Lureau, F.; Matras, G.; Chalus, O.; Derycke, C.; Morbieu, T.; Radier, C.; Casagrande, O.; Laux, S.; Ricaud, S.; Rey, G.; et al. High-energy hybrid femtosecond laser system demonstrating $2 \times 10 \mathrm{PW}$ capability. High Power Laser Sci. Eng. 2020, 8, 43. [CrossRef]

3. Daido, H.; Nishiuchi, M.; Pirozhkov, A.S. Review of laser-driven ion sources and their applications. Rep. Prog. Phys. 2012, 75, 56401. [CrossRef] [PubMed]

4. Wille, H.; Rodríguez, M.; Kasparian, J.; Mondelain, D.; Yu, J.; Mysyrowicz, A.; Sauerbrey, R.; Wolf, J.P.; Wöste, L. Teramobile: A mobile femtosecond-terawatt laser and detection system. Eur. Phys. J. Appl. Phys. 2002, 20, 183-190. [CrossRef]

5. Le Garrec, B.; Sebban, S.; Margarone, D.; Precek, M.; Weber, S.; Klimo, O.; Korn, G.; Rus, B. ELI-beamlines: Extreme light infrastructure science and technology with ultra-intense lasers. In Proceedings of the High Energy/ Average Power Lasers and Intense Beam Applications VII, San Francisco, CA, USA, 2-4 February 2014; Davis, S.J., Heaven, M.C., Schriempf, J.T., Eds.; SPIE: Washington, DC, USA, 2014; Volume 8962, p. 89620.

6. Gschwendtner, E.; Adli, E.; Amorim, L.; Apsimon, R.; Assmann, R.; Bachmann, A.M.; Batsch, F.; Bauche, J.; Berglyd Olsen, V.K.; Bernardini, M.; et al. AWAKE, The Advanced Proton Driven Plasma Wakefield Acceleration Experiment at CERN. Nucl. Instrum. Methods Phys. Res. Sect. A Accel. Spectrom. Detect. Assoc. Equip. 2016, 829, 76-82. [CrossRef]

7. Martin, M. Laser accelerated radiotherapy: Is it on its way to the clinic? J. Natl. Cancer Inst. 2009, 101, 450-451. [CrossRef]

8. Ledingham, K.W.D.; Bolton, P.R.; Shikazono, N.; Ma, C.-M.C. Towards Laser Driven Hadron Cancer Radiotherapy: A Review of Progress. Appl. Sci. 2014, 4, 402-443. [CrossRef]

9. Fan, J.; Luo, W.; Fourkal, E.; Lin, T.; Li, J.; Veltchev, I.; Ma, C.-M. Shielding design for a laser-accelerated proton therapy system. Phys. Med. Biol. 2007, 52, 3913-3930. [CrossRef] [PubMed]

10. Bayart, E.; Flacco, A.; Delmas, O.; Pommarel, L.; Levy, D.; Cavallone, M.; Megnin-Chanet, F.; Deutsch, E.; Malka, V. Fast dose fractionation using ultra-short laser accelerated proton pulses can increase cancer cell mortality, which relies on functional PARP1 protein. Sci. Rep. 2019, 9. [CrossRef]

11. Pomerantz, I.; McCary, E.; Meadows, A.R.; Arefiev, A.; Bernstein, A.C.; Chester, C.; Cortez, J.; Donovan, M.E.; Dyer, G.; Gaul, E.W.; et al. Ultrashort Pulsed Neutron Source. Phys. Rev. Lett. 2014, 113, 184801. [CrossRef]

12. Chen, S.N.; Negoita, F.; Spohr, K.; d'Humières, E.; Pomerantz, I.; Fuchs, J. Extreme brightness laser-based neutron pulses as a pathway for investigating nucleosynthesis in the laboratory. Matter Radiat. Extrem. 2019, 4, 054402. [CrossRef] 
13. Nakatsutsumi, M.; Appel, K.; Baehtz, C.; Chen, B.; Cowan, T.E.; Göde, S.; Konopkova, Z.; Pelka, A.; Priebe, G.; Schmidt, A.; et al. Femtosecond laser-generated high-energy-density states studied by x-ray FELs. Plasma Phys. Control. Fusion 2017, $59,14028$. [CrossRef]

14. Snavely, R.A.; Key, M.H.; Hatchett, S.P.; Cowan, T.E.; Roth, M.; Phillips, T.W.; Stoyer, M.A.; Henry, E.A.; Sangster, T.C.; Singh, M.S. Intense high-energy proton beams from petawatt-laser irradiation of solids. Phys. Rev. Lett. 2000, 85, 2945. [CrossRef]

15. Hatchett, S.P.; Brown, C.G.; Cowan, T.E.; Henry, E.A.; Johnson, J.S.; Key, M.H.; Koch, J.A.; Langdon, A.B.; Lasinski, B.F.; Lee, R.W. Electron, photon, and ion beams from the relativistic interaction of Petawatt laser pulses with solid targets. Phys. Plasmas 2000, 7, 2076. [CrossRef]

16. Roth, M.; Schollmeier, M. Ion Acceleration: TNSA. In Laser-Plasma Interactions and Applications; Springer: Heidelberg, Germany, 2013; pp. 303-350.

17. Hegelich, B.M.; Pomerantz, I.; Yin, L.; Wu, H.C.; Jung, D.; Albright, B.J.; Gautier, D.C.; Letzring, S.; Palaniyappan, S.; Shah, R.; et al. Laser-driven ion acceleration from relativistically transparent nanotargets. New J. Phys. 2013, 15, 85015. [CrossRef]

18. Henig, A.; Steinke, S.; Schn urer, M.; Sokollik, T.; H orlein, R.; Kiefer, D.; Jung, D.; Schreiber, J.; Hegelich, B.M.; Yan, X.Q.; et al. Radiation-Pressure Acceleration of Ion Beams Driven by Circularly Polarized Laser Pulses. Phys. Rev. Lett. 2009, 103, 245003. [CrossRef] [PubMed]

19. Morrison, J.T.; Feister, S.; Frische, K.D.; Austin, D.R.; Ngirmang, G.K.; Murphy, N.R.; Orban, C.; Chowdhury, E.A.; Roquemore, W.M. MeV proton acceleration at $\mathrm{kHz}$ repetition rate from ultra-intense laser liquid interaction. New J. Phys. 2018, 20,22001 [CrossRef]

20. Gauthier, M.; Curry, C.B.; Göde, S.; Brack, F.E.; Kim, J.B.; MacDonald, M.J.; Metzkes, J.; Obst, L.; Rehwald, M.; Rödel, C.; et al. High repetition rate, multi-MeV proton source from cryogenic hydrogen jets. Appl. Phys. Lett. 2017, 111, 114102. [CrossRef]

21. Gershuni, Y.; Roitman, D.; Cohen, I.; Porat, E.; Danan, Y.; Elkind, M.; Levanon, A.; Louzon, R.; Reichenberg, D.; Tsabary, A.; et al. A gatling-gun target delivery system for high-intensity laser irradiation experiments. Nucl. Instrum. Methods Phys. Res. Sect. A Accel. Spectrom. Detect. Assoc. Equip. 2019, 934, 58-62. [CrossRef]

22. Gershuni, Y.; Elkind, M.; Cohen, I.; Tsabary, A.; Sarkar, D.; Pomerantz, I. Automated Delivery of Microfabricated Targets for Intense Laser Irradiation Experiments. J. Vis. Exp. 2021, e61056. [CrossRef]

23. Haberberger, D.; Tochitsky, S.; Fiuza, F.; Gong, C.; Fonseca, R.A.; Silva, L.O.; Mori, W.B.; Joshi, C. Collisionless shocks in laser-produced plasma generate monoenergetic high-energy proton beams. Nat. Phys. 2012, 8, 95-99. [CrossRef]

24. Puyuelo-Valdes, P.; Henares, J.L.; Hannachi, F.; Ceccotti, T.; Domange, J.; Ehret, M.; D’humieres, E.; Lancia, L.; Marquès, J.-R.; Ribeyre, X.; et al. Proton acceleration by collisionless shocks using a supersonic H 2 gas-jet target and high-power infrared laser pulses articles you may be interested in Proton acceleration by collisionless shocks using a supersonic $\mathrm{H} 2$ gas-jet target and high-power infra. Phys. Plasmas 2019, 26, 123109. [CrossRef]

25. Sylla, F.; Flacco, A.; Kahaly, S.; Veltcheva, M.; Lifschitz, A.; Malka, V.; D’Humières, E.; Andriyash, I.; Tikhonchuk, V. Short intense laser pulse collapse in near-critical plasma. Phys. Rev. Lett. 2013, 110. [CrossRef]

26. Henares, J.L.; Puyuelo-Valdes, P.; Hannachi, F.; Ceccotti, T.; Ehret, M.; Gobet, F.; Lancia, L.; Marquès, J.R.; Santos, J.J.; Versteegen, M.; et al. Development of gas jet targets for laser-plasma experiments at near-critical density. Rev. Sci. Instrum. 2019, 90. [CrossRef]

27. Levy, D.; Bernert, C.; Rehwald, M.; Andriyash, I.A.; Assenbaum, S.; Kluge, T.; Kroupp, E.; Obst-Huebl, L.; Pausch, R.; SchulzeMakuch, A.; et al. Laser-plasma proton acceleration with a combined gas-foil target. New J. Phys. 2020, 22, 103068. [CrossRef]

28. Leemans, W.P.; Gonsalves, A.J.; Mao, H.S.; Nakamura, K.; Benedetti, C.; Schroeder, C.B.; Toth, C.; Daniels, J.; Mittelberger, D.E.; Bulanov, S.S.; et al. Multi-GeV Electron Beams from Capillary-Discharge-Guided Subpetawatt Laser Pulses in the Self-Trapping Regime. Phys. Rev. Lett. 2014, 113, 245002. [CrossRef] [PubMed]

29. Faure, J.; Rechatin, C.; Norlin, A.; Lifschitz, A.; Glinec, Y.; Malka, V. Controlled injection and acceleration of electrons in plasma wakefields by colliding laser pulses. Nature 2006, 444, 737-739. [CrossRef] [PubMed]

30. Cecchetti, C.A.; Betti, S.; Gamucci, A.; Giulietti, A.; Giulietti, D.; Koester, P.; Labate, L.; Patak, N.; Vittori, F.; Ciricosta, O.; et al. High-charge, multi-MeV electron bunches accelerated in moderate laser-plasma interaction regime. In AIP Conference Proceedings; AIP Publishing LLC: New York, NY, USA, 2010; Volume 1209, pp. 19-22. [CrossRef]

31. Giulietti, D.; Galimberti, M.; Giulietti, A.; Gizzi, L.; Borghesi, M.; Balcou, P.; Rousse, A.; Rousseau, J. High-energy electron beam production by femtosecond laser interactions with exploding-foil plasmas. Phys. Rev. E 2001, 64, 15402. [CrossRef]

32. Kneip, S.; Nagel, S.R.; Martins, S.F.; Mangles, S.P.D.; Bellei, C.; Chekhlov, O.; Clarke, R.J.; Delerue, N.; Divall, E.J.; Doucas, G.; et al. Near-GeV acceleration of electrons by a nonlinear plasma wave driven by a self-guided laser pulse. Phys. Rev. Lett. 2009, 103, 035002. [CrossRef]

33. Giulietti, D.; Galimberti, M.; Giulietti, A.; Gizzi, L.A.; Numico, R.; Tomassini, P.; Borghesi, M.; Malka, V.; Fritzler, S.; Pittman, M.; et al. Production of ultracollimated bunches of multi-MeV electrons by $35 \mathrm{fs}$ laser pulses propagating in exploding-foil plasmas. Phys. Plasmas 2002, 9, 3655. [CrossRef]

34. Sequoia HD, Amplitude Tech. Available online: https://amplitude-technologies.pagesperso-orange.fr/sequoia.htm (accessed on 7 June 2021).

35. Porat, E.; Levanon, A.; Roitman, D.; Cohen, I.; Louzon, R.; Pomerantz, I. Towards direct-laser-production of relativistic surface harmonics. In Relativistic Plasma Waves and Particle Beams as Coherent and Incoherent Radiation Sources III; SPIE: Prague, Czech Republic, 2019; p. 17. 
36. Cohen, I.; Levanon, A.; Roitman, D.; Shohat, D.; Urisman, E.; Pomerantz, I. Cat's cradle: A compact, 3D mounted, 90-ns optical delay-line for laser-electron acceleration. Laser Accel. Electrons Protons Ions V 2019, 11037, 38. [CrossRef]

37. Morrison, J.T.; Willis, C.; Freeman, R.R.; van Woerkom, L. Design of and data reduction from compact Thomson parabola spectrometers. Rev. Sci. Instrum. 2011, 82, 33506. [CrossRef] [PubMed]

38. Bell, D.; Garratt-Reed, A. Energy Dispersive X-ray Analysis in the Electron Microscope. Garland Science: New York, NY, USA, 2003.

39. Gonsior, B. Chapter 3 Particle Induced X-Ray Emission (PIXE). In Techniques and Instrumentation in Analytical Chemistry; Elsevier: Amsterdam, The Netherlands, 1988; Volume 8, pp. 123-179.

40. Karydas, A.G.; Streeck, C.; Bogdanovic Radovic, I.; Kaufmann, C.; Rissom, T.; Beckhoff, B.; Jaksic, M.; Barradas, N.P. Ion beam analysis of $\mathrm{Cu}(\mathrm{In}, \mathrm{Ga}) \mathrm{Se} 2$ thin film solar cells. Appl. Surf. Sci. 2015, 356, 631-638. [CrossRef]

41. Nam, D.; Opanasyuk, A.S.; Koval, P.V.; Ponomarev, A.G.; Jeong, A.R.; Kim, G.Y.; Jo, W.; Cheong, H. Composition variations in $\mathrm{Cu} 2 \mathrm{ZnSnSe} 4$ thin films analyzed by X-ray diffraction, energy dispersive $\mathrm{X}$-ray spectroscopy, particle induced X-ray emission, photoluminescence, and Raman spectroscopy. Thin Solid Films 2014. [CrossRef]

42. Wyroba, E.; Suski, S.; Miller, K.; Bartosiewicz, R. Biomedical and agricultural applications of energy dispersive X-ray spectroscopy in electron microscopy. Cell. Mol. Biol. Lett. 2015, 20, 488-509. [CrossRef]

43. Sharmila, P.P.; Tharayil, N.J. DNA Assisted Synthesis, Characterization and Optical Properties of Zinc Oxide Nanoparticles. Int. J. Mater. Sci. Eng. 2014. [CrossRef]

44. Mirani, F.; Maffini, A.; Casamichiela, F.; Pazzaglia, A.; Formenti, A.; Dellasega, D.; Russo, V.; Vavassori, D.; Bortot, D.; Huault, M.; et al. Integrated quantitative PIXE analysis and EDX spectroscopy using a laser-driven particle source. Sci. Adv. 2021, 7. [CrossRef]

45. Runkle, R.C.; White, T.A.; Miller, E.A.; Caggiano, J.A.; Collins, B.A. Photon and neutron interrogation techniques for chemical explosives detection in air cargo: A critical review. Nucl. Instrum. Methods Phys. Res. Sect. A Accel. Spectrom. Detect. Assoc. Equip. 2009, 603, 510-528. [CrossRef]

46. Overley, J.C.; Chmelik, M.S.; Rasmussen, R.J.; Schofield, R.M.S.; Lefevre, H.W. Explosives detection through fast-neutron timeof-flight attenuation measurements. Nucl. Instrum. Methods Phys. Res. Sect. B Beam Interact. Mater. Atoms 1995, 99, 728-732. [CrossRef]

47. Fink, C.L.; Micklich, B.J.; Yule, T.J.; Humm, P.; Sagalovsky, L.; Martin, M.M. Evaluation of neutron techniques for illicit substance detection. Nucl. Instrum. Methods Phys. Res. Sect. B Beam Interact. Mater. Atoms 1995, 99, 748-752. [CrossRef]

48. Rynes, J.; Bendahan, J.; Gozani, T.; Loveman, R.; Stevenson, J.; Bell, C. Gamma-ray and neutron radiography as part of a pulsed fast neutron analysis inspection system. Nucl. Instrum. Methods Phys. Res. Sect. A Accel. Spectrom. Detect. Assoc. Equip. 1999, 422, 895-899. [CrossRef]

49. Rapiscan Systems. Available online: https:/ / www.rapiscansystems.com/en/products/cvi (accessed on 7 June 2021).

50. Eberhardt, J.E.; Rainey, S.; Stevens, R.J.; Sowerby, B.D.; Tickner, J.R. Fast neutron radiography scanner for the detection of contraband in air cargo containers. Appl. Radiat. Isot. 2005, 63, 179-188. [CrossRef] [PubMed]

51. Battistoni, G.; Muraro, S.; Sala, P.R.; Cerutti, F.; Ferrari, A. Others The FLUKA code: Description and benchmarking. In AIP Conference Proceedings; AIP Publishing LLC: New York, NY, USA, 2007; AIP Publishing LLC: New York, NY, USA, 2007; Volume 896, pp. 31-49.

52. Reusen, I.; Andreyev, A.; Andrzejewski, J.; Bijnens, N.; Franchoo, S.; Huyse, M.; Kudryavtsev, Y.; Kruglov, K.; Mueller, W.F.; Piechaczek, A.; et al. $\beta$-decay study of $[54,55]$ Ni produced by an element-selective laser ion source. Phys. Rev. C Nucl. Phys. 1999, 59, 2416-2421. [CrossRef]

53. Ong, W.J.; Langer, C.; Montes, F.; Aprahamian, A.; Bardayan, D.W.; Bazin, D.; Brown, B.A.; Browne, J.; Crawford, H.; Cyburt, R.; et al. Low-lying level structure of Cu 56 and its implications for the rp process. Phys. Rev. C 2017, 95, 055806. [CrossRef] 